de atletismo através do nível de higiene oral, de hemorragia gengival, de cárie e de erosão dentária; b) determinar os fatores, relacionados e não relacionados com a prática desportiva, que influenciam o estado de saúde oral dos atletas. Materiais e métodos: Foi realizado um estudo observacional e transversal, no qual foi aplicado um questionário aos atletas, para conhecimento dos comportamentos relacionados com a atividade desportiva e com a saúde oral. Foi também feita uma observação intraoral para recolha de informação sobre o nível de higiene oral (IHO-S), a experiência de cárie (ICDAS II) e a erosão dentária (BEWE). Foi efetuada a análise descritiva dos dados e os testes do Qui-quadrado, Mann-Whitney e Kruskal-Wallis $(\alpha=0,05)$. Resultados: A amostra incluiu 40 atletas, com uma média de idades de 24,5 anos. A maioria dos atletas $(56,4 \%)$ apresentou um nível de higiene oral bom. A prevalência de hemorragia gengival foi $85 \%$ e a de cárie $92,5 \%$, sendo o CA-6POD médio $6,7(d p=5,40)$. A prevalência de erosão foi $40 \%$, sendo o valor ' 3 ', do índice BEWE, o mais alto encontrado. Verificou-se uma associação entre a autoperceção do estado de saúde oral com o nível de higiene oral e com a prevalência de cárie; o consumo de suplementos alimentares com a presença de hemorragia gengival e de cárie; e os anos de prática no alto rendimento com a presença de cárie e de erosão. Conclusões: A população estudada apresenta fragilidades relativamente à sua saúde oral e aos comportamentos a esta associados. Alguns aspetos relacionados com a prática desportiva influenciaram a saúde oral dos atletas. Justifica-se a implementação de estratégias preventivas específicas, que envolvam os atletas de alto rendimento e a sua rede de suporte pessoal e desportiva. http://doi.org/10.24873/j.rpemd.2019.12.591

\#130 Avaliação da saúde oral e geral da população
geriátrica utente da FMDUL Joana Martins*, Mário Bernardo, Sofia Arantes e Oliveira

Faculdade de Medicina Dentária da Universidade de Lisboa

Objetivos: Este estudo teve como objetivo a caracterização da saúde oral e geral da população geriátrica utente da Faculdade de Medicina Dentária da Universidade de Lisboa (FMDUL). Materiais e métodos: A população deste estudo consistiu nos pacientes geriátricos utentes da clínica da FMDUL, cuja primeira consulta decorreu entre 1 de março de 2006 e 20 de junho de 2018. Foi selecionada uma amostra correspondente a 10\% da população. A recolha de dados referentes à saúde oral e geral foi efetuada através da consulta dos processos físicos. A análise estatística foi efetuada recorrendo ao software IBM $^{\circledR}$ SPSS $^{\circledR}$ Statistics, versão 25.0 para Windows, e o nível de significância foi fixado em 5\%. Resultados: A amostra foi constituída por 617 indivíduos com média de idades de 71,81, maioritariamente do género feminino e residente em zonas urbanas. A média de CPOD foi de 19,12, sendo que 100\% dos indivíduos apresentavam experiência de cárie, 3,1\% eram edêntulos, 15,6\% utilizavam pelo menos uma prótese total, 36,7\% prótese parcial removível e 15,3\% prótese fixa. A prevalência de xerostomia foi de $2,3 \%$. As doenças articulares $(20,2 \%)$ e hipertensão arterial (19,9\%) foram as mais prevalentes sendo que $81,1 \%$ dos pacientes apresentavam pelo menos uma patologia e a maio- ria dos pacientes tomava pelo menos um fármaco, dos quais os antihipertensores e antidislipidémicos foram os mais frequentes (38,2\% e $23,7 \%$ respetivamente). As doenças cardiovasculares foram significativamente superiores no género masculino $(p=0,026)$ e, as doenças articulares, toma de bifosfonatos e antidislipidémicos no género feminino $(p<0,001$, $p=0,01$ e $p=0,021$ respetivamente). $O$ valor de CPOD foi significativamente superior no género feminino $(p<0,001)$, em idades superiores $(p=0,032)$ e em pacientes com doenças articulares $(p=0,010)$. A utilização de pelo menos uma prótese total foi superior no grupo etário $\geq 80(p=0,003)$. A presença de xerostomia esteve associada ao diagnóstico de $\operatorname{AVC}(p=0,010)$ e toma de antidislipidémicos $(p=0,042)$. Conclusões: A prevalência de cárie dentária, doenças crónicas e toma de fármacos é elevada na população geriátrica utente da FMDUL.

http://doi.org/10.24873/j.rpemd.2019.12.592

\section{\#131 Modelo preditivo do impacto do VIH na Qualidade de Vida Relacionada com a Saúde Oral CrossMark}

Rúben Rocha Trindade, Joana Marques*, Duarte Marques, Marcos Veiga, António Mata

Centro Médico Dentário da Associação ABRAÇO, Faculdade de Medicina Dentária da Universidade de Lisboa, LIBPhys

Objetivos: Avaliar o impacto da infecção por VIH-1 através da elaboração de um modelo preditivo da qualidade de vida relacionada com a saúde oral (QVRSO) em doentes com necessidades de tratamentos dentários, recorrendo ao questionário Oral Health Impact Profile-49 (OHIP-49). Materiais e métodos: Realizou-se um estudo seccional cruzado que comparou a QVRSO em doentes VIH negativos (grupo 1, n=94) e VIH-1 positivos (grupo 2, n=626) do mesmo meio sócio-económico. As diversas pontuações do OHIP-49, quer total quer dos domínios que a constituem, foram determinadas pela soma dos produtos entre o impacto de cada pergunta e respetiva ponderação e apresentadas sob a forma de média \pm erro do padrão da média. Foi realizada uma análise de regressão linear múltipla no sentido de determinar a contribuição de cada uma das variáveis preditivas na pontuação total e subtotal do OHIP-49. Resultados: O grupo 2 apresentou pontuações significativamente mais elevadas quer para a pontuação total $(169,02 \pm 4,86$ vs. $94,41 \pm 8,38)$ quer para as diferentes subescalas do OHIP-49. Foi determinada uma equação de regressão linear múltipla e preditiva da pontuação total do OHIP-49 $\mathrm{F}(7,610)=61,016, \mathrm{p}<0,001$, com valor $\mathrm{R} 2$ ajustado de 0,405 . Fixando as mesmas variáveis para ambos os grupos a predição da pontuação total para o grupo 1 (seropositivo) é 63,304 pontos superior ao grupo 2. As variáveis infecção pelo VIH-1', 'número de dentes cariados", "necessidades prostodônticas", "care index", "uso de drogas", "empregabilidade" e "idade" apresentaram um efeito independente nas pontuações do OHIP-49. Conclusões: A infeção por VIH-1 tem um impacto independente e significativo na QVRS, estando associada à sua degradação. Contrariamente ao care index, que apresentou um impacto independente e positivo na QVRSO, o número de dentes cariados, as necessidades prostodônticas e o uso de drogas apresentaram um impacto negativo na QVRSO destes doentes. http://doi.org/10.24873/j.rpemd.2019.12.593 